\title{
PENGARUH PEMBERIAN KOMPRES PANAS UNTUK MENGURANGI NYERI PERSALINAN PADA KALA I FASE AKTIF DI BPM SUSI HERSAPTITI DESA KALIKEBO, TRUCUK KLATEN, JAWA TENGAH TAHUN 2014
}

\author{
Fatimah Sari $^{1}$, Nova Wijarnarko ${ }^{2}$, Mustika Pramestyani ${ }^{3}$ \\ ${ }^{1,3}$ D3 Kebidanan STIKes Guna Bangsa Yogyakarta, ${ }^{2}$ BAPELKES Kalasan Yogyakarta
}

\begin{abstract}
Background: Mothers who give birth often experience pain and no pain will rarely cause anxiety, muscles become spastic, rigid, narrow birth canal and less relaxation. It also can cause fatigue in a decrease uterine contractions. The number of women who want to give birth with the birth process that takes place without pain, the various efforts undertaken to reduce pain in childbirth,both pharmacological and non-pharmacological. One alternative non-pharmacological administration of hot compress on the back.

Objective: Knowing the effect of hot compress compresses to reduce pain in active phase of the first stage of labor on Susie Hersaptiti BPM.

Methods: The study was a Quasi Experiment. With one group pre-test post-test. Respondents in this study were all women giving birth in the active phase of the first stage in BPM Susi Hersaptiti the number of subjects 10 mothers, who were taken by means of non-probability sampling with quotas techniques.

Results: The test results analysis using the Wilcoxon test marked ratings obtained asymp. Sing (2-tailed) for the effect of hot compress is (0.004) with the $\mathrm{a}=0.05$ it can be concluded that Ho is rejected $\mathrm{Ha}$ accepted. There is the effect of hot compresses to reduce pain active phase of the first stage of labor.
\end{abstract}

Keywords: active phase of the first stage of labor, pain intensity, Hot Compress

\section{PENDAHULUAN}

Menurut Potter (2005) metode nonfarmakologi yang dapat dilakukan melalui kegiatan tanpa obat antara lain dengan teknik distraksi,biofeedback.,hypnosis-diri, mengurangi persepsi nyeri, dan stimulasi kutaneus (masase, mandi air hangat, kompres panas atau dingin, stimulasi saraf 
elektrik transkutan). Pengendalian nyeri non farmakologi menjadi lebih murah, simpel,efektif dan tanpa efek yang merugikan. Disamping itu juga dapat meningkatkan kepuasan selama persalinan karena ibu dapat mengontrol perasaan dan kekuatanya (Arifin, 2007).

Kompres panas yang merupakan suatu metode non farmakologi dianggap sangat efektif dalam menurunkan kasuskasus nyeri. Kompres panas adalah tindakan dengan memberikan kompres hangat yang bertujuan memenuhi kebutuhan rasa nyaman, mengurangi atau membebaskan nyeri, mencegah terjadinya spasme otot, dan memberikan rasa hangat (iliyah dan hidayat, 2006). panas juga bisa merangsang serat saraf yang menutup gerbang sehingga transmisi implus nyeri ke medulla spinalis dan otak dapat dihambat (price, 2005).

Data yang didapatkan dari study pendahuluan yang dilakukan pada bulan april 2014 di BPM Susi Hersaptiti. Desa kali kebo,Rt 13 Rw 4, Trucuk, Klaten, Jawa tengah. Metode yang dilakukan untuk pemenuhan rasa nyaman (bebas nyeri) dalam proses persalinan adalah asuhan sayang ibu, pendampingan suami dalam persalinan, dan masase punggung. Sedangkan pemberian kompres air hangat belum pernah diterapkan. Berdasarkan fenomena diatas peneliti ingin melakukan penelitian tentang pengaruh pemberian kompres air hangat terhadap rasa nyaman dalam proses persalinan kala I fase aktif.

Persalinan lama dapat di sebabkan oleh adanya rasa nyeri yang hebat. Nyeri pada persalian bukan hal baru dikenal sekarang tetapi sudah ada sejak zaman dahulu. Ibu-ibu yang akan melahirkan sering mengalami nyeri dan tidak jarang nyeri akan menimbulkan rasa cemas, otot menjadi spastik,kaku,jalan lahir menjadi sempit dan kurang relaksasi. Selain itu juga dapat menyebabkan keletihan pada penurunan kontraksi uterus. Nyeri yang hebat akan berpengaruh buruk pada fisilogis persalinan, walaupun nyeri merupakan salah satu mekanisme pertahan alami tubuh yaitu suatu peringatan akan adanya bahaya (Suheinimi, 2008).

\section{PEMBAHASAN}

1. Karakteristik ibu

a. Usia Ibu

Pada penelitian ini, rata-rata ibu melahirkan di BPM Susi Hersaptiti menunjukan bahwa dari 10 responden paling banyak berusia antara 20-35 tahun yaitu sebanyak $80 \%$ responden, responden yang berusia $<20$ tahun sebanyak $10 \%$ responden, responden yang berusian $>35$ tahun sebanyak $10 \%$ responden. Hal ini menunjukan hanya sedikit yaitu $20 \%$ yang menunjukan resiko tinggi, yang mungkin dialami ibu maupun janin.

seiring bertambahnya usia dan pemahaman terhadap rasa nyeri. Hal ini sesuai dengan yang disampaikan oleh Yuliatun (2008) bahwa otak mengalami degenarasi seiring dengan pertambahan umur seseorang, sehingga orang yang berumur lebih tua cenderung mempunyai ambang nyeri yang lebih rendah dan lebih banyak mengalami penurunan sensasi nyeri.

b. Jumlah kehamilan

Tabulasi silang antara jumlah kehamilan dan intensitas nyeri sebelum pemberian kompres panas pada punggung pada kala 1 fase aktif untuk mengurangi nyeri pada persalinan terhadap sepuluh subyek penelitian berdasarkan hasil penelitian diketahui hasil dari 10 responden, menunjukan bahwa $30 \%$ responden 
ibu primigravida dan sebanyak $70 \%$ Ibu multigravida. Data primigravida dan multigravida tidak berdistribusi secara normal sehingga tidak memiliki kemaknaan secara statistik, dan tidak bisa mendukung teori yang ada.

Bagi ibu primigravida belum mempunyai pengalaman melahirkan jika dibandingkan dengan ibu multigravida. Menurut Bobak (2004) pengalaman melahirkan sebelumnya dapat mempengaruhi respon ibu terhadap sensasi nyeri. Bagi ibu primigravida yang belum mempunyai pengalaman melahirkan dapat menyebabkan ibu stres atau merasa takut yang ternyata secara fisiologis dapat menyebabkan kontraksi uterus menjadi terasa semakin nyeri. Ibu dalam kondisi bersalin mempunyai kecenderungan untuk mengalami stress yang akan merangsang tubuh mengeluarkan hormon stessor yaitu hormon kotekolamin dan hormon adrenalin. Kotekolamin akan dikeluarkan pada saat terjadi kontraksi yang dipicu oleh rasa takut dan kecemasan pada saat melahirkan. Akibatnya uterus menjadi semakin tegang sehingga aliran darah dan oksigen ke dalam otot uterus berkurang karena arteri mengecil dan menyempit yang berakibat pada rasa nyeri yang hebat.

Sedangkan pada ibu multigravida sudah pernah melahirkan sehingga sudah mempunyai pengalaman nyeri saat melahirkan akan mampu merespon rasa nyeri tersebut. Ibu melahirkan dalam keadaan rileks, semua lapisan otot dalam rahim akan berkerja sama secara harmonis sehingga persalinan akan berjalan lancar, mudah dan nyaman (Bobak. L,2004).

Menurut Hartati (2005), Faktor psikis yang berupa rasa takut dan cemas yang berlebihan akan mempengaruhi intensitas nyeri. Setiap ibu mempunyai versi sendiri-sendiri tentang nyeri persalinan, karena ambang batas rangsang nyeri setiap orang berbeda-beda dan subyektif. Beberapa ibu bahkan tidak merasa sakit sama sekali tapi hanya perutnya yang terasa kencang. Tetapi ada juga merasakan nyeri yang hebat dan tidak tertahankan lagi. Beragam respon itu merupakan suatu mekanisme proteksi diri dari rasa nyeri yang dirasakan.

\section{c. Intensititas Nyeri sebelum dan sesudah diberikan kompres panas}

Berdasarkan hasil penelitian bahwah dari 10 responden, sebelum diberikan kompres panas sebanyak $30 \%$ mengatakan nyeri berat terkontrol, dan $70 \%$ yang lainnya mengatakan nyeri berat tidak terkontrol. Nyeri merupakan fenomena multifaktorial, yang subjektif, personal, dan kompleks yang di pengaruhi oleh beberapa faktor diantaranya psikologis, dan psikis. Hal ini sesuai dengan teori menurut Hartati (2005). Faktor fisiologis yang dimaksud adalah kontraksi. Gerakan otot uterus menimbulkan rasa nyeri karena saat itu otot-otot uterus memanjang dan kemudian memendek. Serviks juga akan melunak, menipis dan mendatar, kemudian ditarik. Saat itulah kepala janin menekan mulut rahim dan terjadi pembukaan. Jadi, kontraksi merupakan bagian dari upaya membuka jalan lahir. Intensitas rasa nyeri akan bertambah lama dan semakin sering sebanding dengan kekuatan kontraksi dan tekanan bayi terhadap struktur panggul, dikuti regangan atau mungkin sampai terjadi perobekan jalan lahir bagian bawah. Rasa sakit pada pembukaan $3 \mathrm{~cm}$ sampai selanjutnya rata-rata $0,5-1 \mathrm{~cm}$ per jam. Maka lama dan frekuensi nyeri makin sering dan semakin bertambah kuat sampai mendekati proses persalinan. 
Hasil Intensitas nyeri sesudah diberi kompres panas menunjukan bahwa dari 10 responden setelah di berikan kompres panas sebanyak $20 \%$ mengatakan nyeri ringan, 50\% mengatakan nyeri sedang, dan $30 \%$ mengatakan nyeri berat terkontrol. Hal ini menunjukan bahwa terdapat penurunan intensitas nyeri setelah dilakukan kompres panas, tetapi penurunan intensitas nyeri tidak sama pada setiap individu. Selama proses persalinan ibu sangat membutuhkan pemenuhan kebutuhan dasar, salah satu kebutuhan dasar yang mutlak harus dipenuhi adalah bebas dari nyeri. Setiap ibu ingin terbebas dari nyeri akibat his. Beberapa bentuk menyamankan ibu secara nonfarmakologis salah satunya adalah dengan kompres panas (Nungraheny,dkk.2010) .

Kompres panas adalah tindakan dengan memberikan kompres panas yang bertujuan memenuhi kebutuhan rasa nyaman, mengurangi atau membebaskan nyeri, mengurangi atau mencegah terjadinya spasme otot dan memberikan rasa panas (Uliyah \& Hidayat, 2006). Panas yang diberikan pada punggung bawah wanita diarea tempat kepala janin menekan tulang belakang akan mengurangi nyeri, panas akan meningkatkan sirkulasi ke area tersebut sehingga memperbaiki anoksia jaringan yang disebabkan oleh tekanan (Varney, 2007).

d. Pengaruh pemberian kompres panas pada persalinan kala 1 fase aktif

Hasil uji analisis dengan menggunakan uji wilcoxon didapatkan asymp. Sing (2-tailed) untuk pengaruh pemberian kompres panas adalah (0.004) dengan $a=0.05$ sehingga dapat disimpulkan bahwa $\mathrm{H}_{\mathrm{o}}$ ditolak dan $\mathrm{H}_{\mathrm{a}}$ diterima. Ada pengaruh pemberian kompres panas untuk mengurangi rasa nyeri pada persalinan kala I fase aktif.

Hasil uraian diatas dapat disimpulkan bahwa pemberian kompres panas berpengaruh terhadap rasa nyeri pada persalinan kala I fase aktif. Hal ini sesuai dengan teori yang menyatakan bahwa pemberian kompres panas merupakan salah satu cara untuk mengurangi rasa nyeri (Uliyah \& Hidayat, 2006). Panas yang diberikan pada punggung bawah wanita diarea tempat kepala janin menekan tulang belakang dan akan mengurangi nyeri, rasa panas akan meningkatkan sirkulasi ke area tersebut sehingga memperbaiki anoksia jaringan yang disebabkan oleh tekanan (Varney, 2007).

Hasil ini juga didukung oleh penelitian yang pernah dilakukan Khusniyah Zulfa \& Rizki Hajar tahun 2012 tentang pengaruh pemberian kompres hangat terhadap rasa nyaman dalam proses persalinan kala I fase aktif BPM Ny Etty Supartiningsih Rahayu Zubaidah. SST Desa Mentoro,Kecamatan Sumobito,kabupaten jombang, pada bulan april sampai mei 2012 yang menyatakan bahwa pemberian kompres hangat dapat memberikan rasa nyaman dalam proses persalinan kala I fase aktif.

\section{SIMPULAN}

1. Mayoritas ibu bersalin di BPM Susi Hersaptiti berusia 20-35 tahun yaitu sebanyak $80 \%$

2. Mayoritas ibu bersalin d BPM Susi Hersaptiti adalah multigravida, yaitu sebanyak $70 \%$.

3. Mayoritas ibu bersalin memiliki skala nyeri berat terkontrol sebelum pemberian kompres panas yaitu $70 \%$ 
4. Mayoritas ibu bersalin memiliki skala nyeri sedang sesudah diberikan kompres panas yaitu $50 \%$.

5. Ada pengaruh pemberian kompres panas untuk mengurangi nyeri persalinan pada persalinan kala I fase aktif

\section{SARAN}

1. Ibu bersalin

Bagi ibu bersalin diharapkan dapat memanfaatkan kompres panas untuk membantu menurunkan intensitas nyeri yang dirasakan

2. Bidan

Dapat dijadikan alternatif pilihan dalam pemberian asuhan persalinan terutama untuk mengurangi rasa nyeri pada persalinan kala I fase aktif dengan pemberian kompres panas

3. Peneliti selanjutnya

Bagi peneliti lain yang berminat mengembangkan masalah ini dengan jumlah sampel yang lebih banyak, penggunan kelompok kontrol agar menguatkan metodelogi yang lain dan penerapan teknologi buli-buli yang berkualitas sehingga akan didapatkan hasil penelitian yang lebih relevan.

\section{DAFTAR PUSTAKA}

Anonim,(2011).Konsep dan Penerapan Metodologi Penelitian IlmuKeperawatan Jakarta: Salemba Medika

Anonim,(2012). AKI di Jawa Tengah Selama 2012 Capai 675 Kasus. (4 Febuari 2013, http://www.jatengtime.com diakses tanggal 20 april 2013).
Anonim,(2013) Menkes Upayakan Kejar Target $M D G$ 's dalam

http://www.dinkesjatengprov.go.id diakses tanggal 9 mei 2013

Andriana,(2007). Melahirkan Tanpa Rasa Sakit. Jakarta: PT Bhuana Ilmu Pupoler Kelompok Gramedia.

Akdon dan Ridwan, (2010). Rumus Dan Data Dalam Analisis Statistika. Bandung:Alfabeta

Arikunto,S,(2010).Prosedur Penelitian :Suatu Pendekatan Praktek.Jakarta : Rineka Cipta

Arummy, A,(2012). Hubungan Pengetahuan Ibu Hamil Tentang Tanda Bahaya Kehamilan dengan Kepatuhan Pemeriksaan Kehamilan di BPS Hartini Klaten .Surakarta. STIKes'Aisyiyah Surakarta

Asmadi,(2008). Teknik Prosedural Keperawatan : Konsep Dan Aplikasi Kebutuhan Dasar Klien.Jakarta :Salemba Medika

Bobak, L,(2010).Buku Ajar Keperawatan martenitas edisi4. Jakarta : ECG

Bare, B.G., dan Smeltzer, S.C.(2007). Buku Ajar Keperawatan Medikal Bedah.Volume 2.Edesi 8.Jakarta :EGC Constance, S.2009. Buku Asuhan Kebidanan. Jakarta: EGC

Danuatmaja, B.(2004). Persalinan Normal Tanpa Rasa Salit.Jakarta: Puspa Swarna

Danuatmaja, B. dan Meiliasari, M,(2008). Persalinan Normal Tanpa Rasa Salit.Jakarta: Puspa swarna

Fauziah,A. Sudarti. dan Judha, M.(2012).Teori Pengukuran Nyeri dan Nyeri persalinan. Yogyakarta: Nuha Medika 
Fraser, D.M,. dan Cooper, M.A.(2009).Buku Ajar Bidan Myles. Ed14. Jakarta: EGC

Harnawatia.(2008). Fisiologi Proses Persalinan Normal. http://harnawatia. Wordpress.com/2008/04/03/fisiologi-

proses-persalinan-normal/. Tanggal 27 April 2012

Hidayat, A.\& Uliyah (2006). Keterampilan Dasar Praktek Klinik Kebidanan. Jakarta : Salemba Medika

Hidayat, A.(2010). Metode Penelitian Kebidanan dan Teknik Analisis Data. Jakarta : Salemba Medika

JNPK-KR.(2008). Asuhan Persalinan Normal dan Inisiasi Menyusu Dini.Jakarta : Jaringan Nasional Pelatihan Klinik.

Khusniyah Zulfa \& Rizki Hajar( 2012). Pengaruh Pemberian Kompres Hangat Terhadap Rasa Nyaman Dalam Proses Persalinan Kala I Fase Aktif BPM Ny Etty Supartiningsih Rahayu Zubaidah. SST Desa Mentoro,Kecamatan Sumobito, Kabupaten Jombang, Pada Bulan April Sampai Mei 2012. Universitas Pesantren Tinggi Darul 'Ulum Jombang

Mawarni.(2010). Nyeri Persalinan. Dalam http://repository.usu.ac.id/bitstream /123456789/18775/5/Chapter \%20I.pdf. Tanggal 14 April 2012

Notoatmodjo, S. 2012. Metodologi Penelitian Kesehatan. Jakarta : PT Rineka Cipta.

Nursalam.(2003). Konsep dan Penerapan Metodologi Penelitian Ilmu Keperawatan.Jakarta :Salemba Medika.
Patree,B.,Walsh, V.L.(2007).Buku Ajar Kebidanan Komunitas, Jakarta : EGC

Prawirohardjo, S.(2010). Ilmu Kebidanan. Jakarta : Yayasan Bina Pustaka Sarwono Prawirohardjo.

Price, S \& Wilson, L,2005. Patofisiologis: Konsep Klinis Proses-Proses Penyakit. Edisi 6. ECG, Jakarta.

Potter, P.A., dan Perry, A, G.(2005).Fundamental Keperawatan .Jakarta : EGC

Riwidikdo.(2007). Statistik Kesehatan. Yogyakarta: Nuha Medika

Saifuddin, A.(2009). Ilmu kebidanan Edisi Keempat.Jakarta: PT Bina Pustaka Sarwono Prawirohardjo

Sugiyono.(2011). Metode Penelitian Kuantitatif Kualitatif dan R\&D. Bandung : Alfabeta.

Sugiyono.(2013). Statistika Untuk Penelitian. Bandung : Alfabeta.

Saunders, W.B.C.(2002). Kamus Saku Kedokteran Dorlan. Jakarta : EGC.

Simkin, P. (2005). Buku Saku Persalinan. Jakarta : EGC

Sulistyawati,A dan Nugraheni, E. (2010). Asuhan Kebidanan Pada Ibu Bersalin. Jakarta : Salemba Medika

Sumarah, dkk.(2009). Asuhan Kebidanan Pada Ibu Bersalin. Yogyakarta : Fitramaya

Tamsuri, A.(2007). Konsep penatalaksanaan nyeri.Jakarta: EGC 
Yanti.(2010).Buku Ajar Asuhan

Kebidanan Persalinan. Yogyakarta:

Pustaka Rihama

Varney, H, dkk.(2007). Buku Ajar Asuhan

Kebidanan.Jakarta : EGC

William,.(2010).Ilmu Kebidanan Patologi

Dan Fisiologi Persalian.

.Yogyakarta:Yayasan Essentia Medica.

Walley, J., Simkim, P., \& Keppler, A.

(2008). Panduan Praktis Bagi Calon Ibu :

Kehamilan Dan Persalian. Jakarta.

Bhuana Ilmu Populer. 